\title{
Cricoesophageal Tendon
}

National Cancer Institute

\section{Source}

National Cancer Institute. Cricoesophageal Tendon. NCI Thesaurus. Code C32399.

The longitudinal fiber of the esophagus connected to the cricoid cartilage of the larynx. 